\title{
Secondary immunodeficiencies with predominant antibody deficiency: multidisciplinary perspectives of Polish experts
}

\author{
KARINA JAHNZ-RÓŻYK ${ }^{1}$, EWA WIĘSIK-SZEWCZYK ${ }^{1}$, JACEK ROLIŃSKI ${ }^{2}$ MACIEJ SIEDLAR \\ WIESŁAW JĘDRZEJCZAK ${ }^{4}$, WOJCIECH SYDOR ${ }^{5}$, AGNIESZKA TOMASZEWSKA ${ }^{4}$
}

\author{
${ }^{1}$ Department of Internal Medicine, Pneumonology, Allergology and Clinical Immunology, Central Clinical Hospital of the Ministry \\ of National Defense, Military Institute of Medicine, Warsaw, Poland \\ ${ }^{2}$ Department of Clinical Immunology, Medical University of Lublin, Lublin, Poland \\ ${ }^{3}$ Department of Clinical Immunology, Institute of Pediatrics, Jagiellonian University Medical College, Krakow, Poland \\ ${ }^{4}$ Department of Hematology, Oncology and Internal Medicine, Medical University of Warsaw, Warsaw, Poland \\ ${ }^{5}$ Department of Rheumatology and Immunology, Jagiellonian University Medical College, Krakow, Poland
}

\begin{abstract}
At present, secondary immune deficiencies have become a clinical problem, recognized in different specialties. The aim of this paper was to increase awareness and support the need for screening at-risk populations. Secondary immune deficiencies result in variety of conditions, but not all of them require immunoglobulin replacement therapy, as specific antibody response might be preserved. Moreover, the management of secondary immune deficiencies vary between countries and different medical disciplines. This literature review presents the most common causes and clinical presentation of secondary immunodeficiencies with predominant impaired antibody production. We present diagnostic guidelines for patients at-risk, with an emphasis on the role of prophylactic vaccination as a treatment and diagnostic tool. This review considers the specificity and disparities of the Polish healthcare system and ultimately, suggests that management teams should include a clinical immunologist experienced in the treatment of humoral immunodeficiencies.
\end{abstract}

Key words: secondary hypogammaglobulinemia, diagnostic workup, immunoglobulin substitution, antibody deficiency, rituximab, subcutaneous immunoglobulin.

(Cent Eur J Immunol 2019; 45 (3): 334-341)

\section{Introduction}

Presently, secondary immune deficiencies (SIDs) have become a clinical problem, recognized in different specialties [1]. SIDs result in a variety of conditions, but not all of them require immunoglobulin replacement therapy $(\operatorname{IgRT})$, as the specific antibody response might be preserved.

The major causes of SIDs in western and central Europe countries include hematological malignancies, mainly, chronic lymphocytic leukemia (CLL), multiple myeloma (MM), and non-Hodgkin lymphoma. Iatrogenic causes include the use of biological therapies, especially targeted B cells, hematopoietic stem cell transplantation [HSCT], and solid organs transplantations [SOT], and further expands the list of specialists involved in care of patients with SID (Table 1). However, the management of SIDs varies regionally and among different specialists $[1,2]$. Current clinical practice does not always reflect treatment guidelines, highlighting the need for robust clinical studies on IgRT in SIDs, and coordination between countries and disciplines [2]. An international online survey of 230 physicians responsible for the diagnosis of SID and prescription of IgRT in patients with hematological malignancies, showed that serum immunoglobulin was measured in $83 \%$ of patients with MM, 76\% with CLL, and 69\% with non Hodgkin lymphoma [2]. Most physicians (85\%) prescribed IgRT after $\geq 2$ severe infections. In Italy, Germany, Spain, and the United States, immunoglobulin use was above average in patients with hypogammaglobulinemia, while considerably fewer patients received IgRT in the UK. The use of subcutaneous immunoglobulin (SCIG) was highest in France (34\%) and lowest in Spain (19\%). In addition, recent data show that IgG monitoring during IgRT is not always conducted [3].

There are no published data for Poland regarding any aspects of SIDs and IgRT. Polish data from primary im-

Correspondence: Ewa Więsik-Szewczyk, PhD, Department of Internal Medicine, Pneumonology, Allergology and Clinical Immunology, Central Clinical Hospital of the Ministry of National Defense, Military Institute of Medicine, 128 Szaserów St., 04-141 Warsaw, Poland, e-mail: ewa.w.szewczyk@gmail.com

Submitted: 26.03.2019; Accepted: 20.11.2019 
mune deficiency (PID) indicated that immunology diagnostic procedures are not wildly recognized. Despite recommendations, vaccination response is assessed in $20 \%$ of adult patients [4]. Patients with a risk of SID sometimes first undergo an immunologic test on a life-threatening infection [5]. Moreover, in Poland, SCIG home therapy is not reimbursed for SID patients, although it is increasingly used in PID [4, 6]. More important problem that is commonly faced is the limited access to intravenous immunoglobulin (IVIg) products; therefore, prescription of IgRT in SID should be well-balanced and justified.

The aim of this paper was to increase the awareness among different specialties and support the need for SID screening in at-risk populations. The review considers the specificity and gaps of the Polish healthcare system. All authors are responsible for diagnosing immunodeficiencies and prescribing IgRT as clinical immunologists (all authors), hematologists (WJ, AT) as well as a rheumatologist (EWS) and a pulmonologist (KJR). Moreover, some of the authors (KJR, MS, EWS) participate in Polish drug programs as members of coordinating teams [7].

\section{SID clinical aspects}

\section{SID in chronic lymphocytic leukemia and multiple myeloma}

In chronic lymphocytic leukemia (CLL), abnormalities of immune system function may affect up to $85 \%$ of patients $[8,9]$. The most common infections are common respiratory and urinary tract infections (UTIs). In immunosuppression naive patients, they are $60 \%$ of bacterial, $25 \%$ of viral, and less common fungal (7\%) infections. The most popular etiological factors of respiratory infections are Staphylococcus aureus, Streptococcus pneumoniae, and Hemophilus influenzae, while in UTIs, it is Escherichia coli. In the course of chemo-immunotherapy used in the treatment of CLL, reactivation of latent viral infections may occur, e.g., with HBV. Treatment with purine analogues that interfere with DNA synthesis reduces CD4+ T cell, lymphocyte, and monocyte counts, which lead to an increased risk of opportunistic infections caused by microorganisms, such as Listeria monocytogenes, Mycobacterium spp., Pneumocystis jiroveci, Herpes simplex, Varicella zoster, Candida spp., Aspergillus spp., and Cryptococcus spp. [10].

Hypogammaglobulinemia is the main factor correlating with an increased risk of infections in CLL. A low concentration of at least one of the major immunoglobulin classes is found at an early stage of the disease, regardless of the tumor mass and often before initiation of cytotoxic treatment. Along with disease duration or progression, immunoglobulin deficiency extends to 2 or 3 classes [11]. In a study by Freeman et al., hypogammaglobulinemia was found in $23 \%$ of 150 patients, out of which $64.6 \%$ had deficiency of at least one IgG subclass, usually IgG3
Table 1. Causes of the most common secondary immunodeficiencies, mainly humoral type $[1,8,25,28,30,32,33$, $35,37,38,40,47]$

\begin{tabular}{|c|c|}
\hline Causes & Examples \\
\hline \multicolumn{2}{|l|}{ Clinical conditions } \\
\hline \multirow{3}{*}{$\begin{array}{l}\text { Lymphoproliferative } \\
\text { diseases }\end{array}$} & Chronic lymphocytic leukemia \\
\hline & Multiple myeloma \\
\hline & Lymphoma \\
\hline \multirow[t]{3}{*}{ Protein loss* } & Renal \\
\hline & Gastrointestinal \\
\hline & Cutaneous loss \\
\hline \multirow[t]{2}{*}{ Transplantation } & Solid organs \\
\hline & Hematopoietic stem cells \\
\hline \multirow[t]{3}{*}{ Infections } & Viral \\
\hline & EBV CMV, HIV - mainly congenital, \\
\hline & parvovirus B19, congenital rubella \\
\hline \multicolumn{2}{|l|}{ Drug-related } \\
\hline \multirow[t]{14}{*}{ Therapies targeting B cells } & Anti-CD20 \\
\hline & Rituximab \\
\hline & Ocrelizumab \\
\hline & Obinutuzumab \\
\hline & Ofatumumab \\
\hline & Anti-CD52 \\
\hline & Alemtuzumab \\
\hline & Anti-CD74 \\
\hline & Milatuzumab \\
\hline & Anti-CD19 \\
\hline & $\begin{array}{l}\text { CD-19-targeted chimeric antigen } \\
\text { receptor T cells }\end{array}$ \\
\hline & Inhibitors B cell maturation \\
\hline & Belimumab \\
\hline & Atacicept \\
\hline Proteasome inhibitors & Bortezomid \\
\hline \multirow[t]{3}{*}{ Tyrosine kinase inhibitors } & Imatinib \\
\hline & Dasatinib \\
\hline & Ibrutinib \\
\hline $\begin{array}{l}\text { Inhibitors interactions } \\
\text { between T cells and B cells }\end{array}$ & Abatacept \\
\hline \multirow{5}{*}{$\begin{array}{l}\text { Purine analogues } \\
\text { Antiepileptics* }\end{array}$} & Fludarabine \\
\hline & Phenytoin \\
\hline & Carbamazepine \\
\hline & Lamotrigine \\
\hline & Valproic acid \\
\hline \multirow[t]{4}{*}{ Other* } & Glucocorticoids \\
\hline & Sulfasalazine \\
\hline & Methotrexate \\
\hline & Leflunomide \\
\hline
\end{tabular}

* specific antibody response preserved despite hypogammaglobulinemia 
[11]. In $8 \%$ of patients with severe recurrent infections, the IgG level was normal, with concurrent deficiency of at least IgG subclass [11]. In CLL patients, an association was found between IgG and IgA deficiency and increased mortality due to bacterial infections [12].

In patients with multiple myeloma (MM), bacterial infections occur at a rate of over $25 \%$ and at one-year follow up, they were the underlying cause in $22 \%$ of deaths in MM. Compared with healthy controls, MM patients have reduced antibodies specific for pneumococci, tetanus, diphtheria, varicella, mumps, measles, and staphylococcal alpha-toxin [13, 14]. Infection risk is the highest in the course of chemotherapy, especially in the initial period of the disease, but also, it persists in the plateau phase. Typical infections in MM patients are RTI, UIT, septic complications, pneumonia, and meningitis $[13,15]$. Savage et al. observed a biphasic pattern in bacterial infections of MM [16]. In 57 patients with MM, 75 infections were analyzed. $S$. pneumoniae and $H$. influenzae occurred at presentation and in early stage of the disease, while Gram-negative bacteria and $S$. aureus were responsible for infections in the advanced phase of diseases and in neutropenic patients, being the cause of death for $92 \%$ of patients $[16,17]$. Although these studies were performed nearly 40 years ago, this bipolar pattern of infections is still present in clinical practice and affects different modes of management.

\section{SID after transplantation of hematopoietic stem cells and solid organs}

Infectious complications are one of the most common causes of deaths in patients after HSCT and SOT [18]. These procedures are associated with a significant risk of immunosuppression development, which often overlaps with immunodeficiency caused by the underlying disease and its previous treatment [18-20]. Restoration of an immune system after transplantation is one of the most important factors that influence the outcome [21, 22]. In this group of patients, SIDs are common, with usually complex pathogenesis, appearing early after transplantation, and may persist for months or even years. Depending on time after transplantation, a deficiency of immunocompetent cells, deficiency of antibodies, or mixed deficiency might dominate [21-23]. Many pre-and post-transplantation factors influence immune restoration, including the recipient's age, underlying disease diagnosis and its advancement at the time of transplantation, previously used methods of treatment, degree of HLA compatibility between the recipient and donor, source of hematopoietic cells, intensity of conditioning, carriage of latent viruses (especially CMV and EBV) by the recipient and donor, and development of graft-versus-host disease [21]. Three basic periods that differ by abnormalities of the immune system and the spectrum of observed infections are arbitrarily defined: phase I is the early (pre-engraftment) phase, when the main risk factors are neutropenia and breakdown of anatomical bar- riers (e.g., gastrointestinal mucositis, presence of a central venous catheter), and includes the time between the transplantation date (day 0 ) and ca. day +30 post-transplantation, i.e., hematological reconstitution; phase II includes days +31 to +100 , with accompanying cellular and humoral immunodeficiency, often related to treatment of acute graft-versus-host disease; and phase III is after day +100 , when humoral immunodeficiencies predominate, and is often associated with chronic graft-versus-host disease and its treatment $[13,19]$. At the same time, hypogammaglobulinemia in transplantation patients was shown to be associated with a significant risk of infectious complications, especially pneumonia, CMV infections, invasive fungal infections, and death [19, 24].

\section{SID in the course of biological therapies}

Biologics, as targeted treatments, significantly interfere with response mechanisms of the immune system. In particular, hypogammaglobulinemia occurs after the use of treatments that inhibit B cell response $[25,26]$. In an analysis of a large group of patients with type B lymphomas published in 2013, in $6.6 \%$ of the patients, IgG deficiency was associated with increased susceptibility to infections, which prompted IgRT initiation [27]. Symptomatic hypogammaglobulinemia was defined as 2 or more non-neutropenic infections that occurred within 6 months. These were mainly sinusitis and pneumonia. The risk factors of infections in patients with hypogammaglobulinemia were at least 2 doses of rituximab and coexisting low levels of $\operatorname{IgM}$ or IgA. The pre-treatment IgG level, exposure to purine analogues, sex, and age ( $\leq 65$ years vs. $>65$ years) as well as histological type of cancer had no impact on infection risk [27].

SIDs are also an increasing problem in patients with autoimmune diseases treated with rituximab [28]. In the described case series, an increased risk of hypogammaglobulinemia in patients with vasculitis and optic neuritis was confirmed [29, 30]. In a group of 101 patients treated with rituximab for various indications, "catastrophic infectious syndrome" occurred in 10 (9.9\% of the analyzed group) patients and was fatal in 7 [31]. In contrast, hypogammaglobulinemia was a rare complication of rituximab treatment in patients with rheumatoid arthritis [32, 33]. However, in clinical trials ( 8 randomized trials and 2 open-label extension trials), exclusion criteria were $\mathrm{IgG}<5.65 \mathrm{~g} / \mathrm{l}$ and $\operatorname{IgM}<0.55 \mathrm{~g} / \mathrm{l}$. It is a challenge to identify early patients at risk for the development of symptomatic hypogammaglobulinemia. Different predisposing factors were suggested depending on the population studied, treatment protocol, and follow-up period. A low IgG level before rituximab treatment, cumulative cyclophosphamide dose, and higher cumulative corticosteroids exposure were reported, but were not confirmed in all studies [27, 34-36].

In Poland, the access to rituximab in autoimmune diseases other than rheumatoid arthritis has so far been limit- 
ed. In connection with the introduction of a drug program and increased use of rituximab in systemic vasculitis, we can expect a larger number of SID patients treated with rituximab, secondary to B cell depletion therapy.

To date, no reports on groups of SID patients, who would require IgRT after the use of other biologicals were found in the literature. The initial reports of high-risk severe infections and hypogammaglobulinemia in patients with systemic lupus erythematosus (SLE) treated with atacicept (TACI receptor antagonist) in combination with mycophenolate mofetil, have not been confirmed in subsequent clinical trials [37]. Belimumab, an anti-BLYSS monoclonal antibody approved for the treatment of SLE, and abatacept (a second signal inhibitor) have to date been considered as safe [38]. However, these data may change along with an extension of their therapeutic indications and a longer period of observation in everyday practice.

\section{Diagnosis of SID}

In 2014, European consensus statement on the determination of serum Ig concentrations and the levels of specific serum antibody titers in response to vaccination was obtained upon as a useful approach for patients' selection in SID, although the need for more research was acknowledged [39].

Evaluation of vaccination response is a critical element of the diagnostic workup [40-42]. It is recommended to test the response to vaccination against pneumococci with the use of a polysaccharide vaccine PPV23. Also, an assessment of specific antibody levels should be measured before vaccination as well as at 4-8 weeks and 6 months after vaccination, to identify patients with an early loss of response to vaccination [43]. Pasiarski et al. reported an increase in plasmablast percentage in the blood one week after a 13-valent pneumococcal conjugate vaccination [44].

Currently, the measurement of specific antibody responses varies across countries. Physicians from Spain, Italy, and the USA measure specific antibody responses more frequently than physicians in general. In the UK and the Republic of Ireland, specific antibody responses are mostly measured after PPV23 vaccination (referred to as test immunization) [45]. Clinical immunologists measure immunologic response more often than other specialists. In an international survey, two - thirds of immunologists and only one-third of physicians reported performing immunizations tests [2].

In Poland, PPV 23 is currently unavailable, but lack of response to the conjugated pneumococcal vaccine might be a criterion for IgRT. An alternative to PPV is testing the response to Salmonella typhi vaccine [46]. In our opinion, reimbursement of the cost of the vaccine and vaccination response before IgRT as well as greater awareness among physicians could increase the vaccination load.

\section{Treatment}

\section{Preventive vaccination}

There has been a long-lasting discussion of vaccination safety and efficacy in chronic inflammatory diseases and malignancy. We would like to underscore that for all patients with a high-risk of SID, selected types of preventive vaccination should be considered $[47,48]$ as a therapeutic option. For example, a special vaccination programme has been developed for transplantation patients $[49,50]$. In CLL patients, pneumococcal conjugate vaccine is recommended. It has also been demonstrated that it is important to vaccinate the patient as early as possible after CLL diagnosis, when normal immunoglobulins are still produced, which ensures better protection after vaccination [51]. Annual preventive vaccination against influenza is also recommended [47, 48]. Vaccination status should be carefully assessed in patients with autoimmune diseases qualified for rituximab treatment. Non-live vaccinations should be administered at least 4 weeks prior to B cell-depleting therapy [52].

\section{Replacement treatment with polyclonal immunoglobulin $\mathbf{G}$}

Institution of IgRT should not be based solely on the IgG result. Eligibility for IgRT should consider severity of infections, concentrations of IgG subclasses, vaccination response, and an assessment of efficacy of prophylactic antibiotic treatment $[36,40]$. The guidelines underscore IgRT only when functional antibody deficiency is proven, independent of a particular threshold level of $\mathrm{IgG}$, which may be even as low as $2.0 \mathrm{~g} / \mathrm{dl}[28,40]$.

The available data on the effects of immunoglobulin replacement in SID showed that it did not reduce mortality. In CLL and MM, randomized trials have been conducted in patients with hypogammaglobulinemia and infections [53-59]. In the IVIG-treated group, the infection rate was lower, antibiotic requirements were reduced, and hospitalization duration was shorter. Limitations of the above studies were small patient groups and relatively short follow-up periods. Therefore, it is recommended to consider replacement in individual cases of patients with CLL, hypogammaglobulinemia, and recurrent infections [60, 61], and with MM, hypogammaglobulinemia, and life-threatening infections [62]. Also, in patients after allo-HSCT and SOT, data on Ig replacement (with both polyvalent and hyperimmune immunoglobulins) are inconclusive, and no uniform guidelines have been formulated so far [9,19]. Several randomized trials have investigated the efficacy of IVIG in the prevention and/or treatment of bacterial, fungal, and viral infections (especially with cytomegalovirus) in cell and organ transplant recipients as well as in the prophylaxis and modification of acute graft-versus-host disease (aGvHD) [9, 63-65]. However, conflicting results were obtained, and one of the trials demonstrated an ele- 
vated risk of hepatic-occlusive disease (VOD/SOS) [65]. Different dosage regimens and immunoglobulin products were used in these trials in heterogeneous patient groups $[9,18,19,65]$. The assessment of efficacy and cost-effectiveness as well as the safety of such an approach, especially in the context of the use of modern infection prophylaxis, raises some concerns $[18,19]$.

\section{Methods of administration and experience in SID}

IgRT can be administered intravenously (IVIG), subcutaneously (SCIG), and via hyaluronidase-facilitated subcutaneous route (fSCIG) [66-70]. The intravenous route is associated with the need for hospitalization and providing venous access. IVIG administration is related to systemic adverse effects that result, for example, from high IgG serum levels immediately after the procedure [66]. Severe complications, such as hemolysis, cardiovascular events, and renal failure, are rare [66]. SCIG and fSCIG are safer methods and do not require vascular access [68]. Because of the limitation of administered volume to $60 \mathrm{ml}$ per single site, subcutaneous use (SCIG) requires dosage at intervals of usually one week, often at several different injection sites, but treatment can be conducted at home after appropriate patient's training $[67,68]$. SCIG provides very stable IgG levels and can be administered by pump or by rapid-push (manual method), depending on the selected Ig product [68]. FSCIG is a method where, due to prior administration of hyaluronidase, it is possible to inject higher individual Ig volumes and dosages into the subcutaneous tissue (up to $500 \mathrm{ml}$ at a single site), with a frequency similar to intravenous products. FSCIG is given via pump in a home setting also [69,70]. Existing experiences with PID indicate benefits from the use of subcutaneous products, which are the preferred Ig replacement method in PID [68, 71]. Clinically, SCIG and fSCIG are used in SID, with good outcomes and a favorable safety profile [3, 72-74]. A recently published study showed that among patients with SID due to hematologic malignancy, $68 \%$ received conventional SCIG and $84 \%$ of them received the treatment via home-based administration [3]. However, clear reasons for classification of patients to specific modes of administration were not given. Formal clinical trials have not been conducted for the use of SCIG and FSCIG in SID.

Recommended doses depend on the product type and are usually 0.2-0.4 g/ $\mathrm{kg} / \mathrm{month}$. Data from Germany show a tendency for low doses, with an average dose of $199 \mathrm{mg} / \mathrm{kg}$ per 4 weeks for IVIG, and $343 \mathrm{mg} / \mathrm{kg}$ per 4 weeks for SCIG [75]. Clinical immunologists were typically present to order higher doses $(0.4-0.5 \mathrm{mg} / \mathrm{kg})$, especially in patients with bronchiectasis, probably as an analogy of PID $[1,2,45]$.

The duration of replacement treatment is often limited to 6-12 months, but clinical practice is not universal. Agostini et al. recommended that treatment discontinuation may be considered in patients with a stable primary condition, who have received IgRT for more than a year and who have not reported infectious episodes during this period [76]. In the German SINGS study, $24.1 \%$ of patients had their treatment temporarily interrupted over a mean of $11.6 \pm 6.3$ months [75]. Recent reports showed that IgRT is given regardless of the season, although discontinuation in the summer was recommended by an expert opinion $[45,75,76]$.

The main method of assessing treatment efficacy is the reduction of infection rate or the decrease in infection severity, but the Ig trough level is also considered [2, 45].

To make recommendations clearer in recent years, several countries developed their own guidelines on the proper use of IgRT in SIDs [77, 78]. They differ by the adopted eligibility criteria, including the number of infections, the need for course of antibiotics prophylaxis, or specific antibody assessment (Table 2).

The guidelines of the European Medicines Agency (EMA) [80] state that patients with severe or recurrent bacterial infections, ineffective antibiotic treatment, and vaccination failure (i.e., failure to mount at least a two-fold rise in an IgG antibody titre to conjugated pneumococcal polysaccharide vaccine) and/or hypogammaglobulinemia (defined as IgG level $<4 \mathrm{~g} / \mathrm{l}$ ), are eligible for IVIG therapy. The recommended primary endpoint to assess treatment efficacy is the rate of serious bacterial infections $(<1.0$ infection/patient/year), which are defined as bacteremia or sepsis, bacterial meningitis, osteomyelitis, septic arthritis, bacterial pneumonia, or visceral abscess. The secondary endpoints are IgG through levels, all other infections, antibiotic treatment, days lost from work or school, hospitalizations, and fever episodes [79]. There are no clear criteria developed for Poland.

\section{Conclusions}

On the basis of the available study results and published meta-analyses, we do not recommend routine replacement treatment with immunoglobulin products in patients with SID.

The decision to initiate replacement therapy should be individualized and based on a combination of clinical history, evidence of infections, and vaccination testing for diagnosis. In Poland, we advocate for reimbursement for vaccines and diagnostic vaccination response in SID before IgRT.

We suggest that management teams should include a clinical immunologist experienced in the treatment of humoral immunodeficiencies.

The use of SC immunoglobulin in patients with SID should be available; however, it is mainly based on limited open trials or cohorts and PID's experience. Formal trials are needed for the use of SCIG and fSCIG in SID.

The authors declare no conflict of interest. 
Table 2. Proposed selection criteria for polyclonal immunoglobulin G replacement therapy in SID in different countries [77-80]

\begin{tabular}{|c|c|c|c|c|}
\hline Country & Infections & Immunization response & IgG level at baseline & Disciplines involved \\
\hline EMA & $\begin{array}{c}\text { Severe or recurrent bacterial } \\
\text { infections }\end{array}$ & $\begin{array}{l}\text { Failure to mount at least a 2-fold } \\
\text { rise in an IgG antibody titer to } \\
\text { pneumococcal polysaccharide } \\
\text { and polypeptide antigen vaccines }\end{array}$ & $<4 \mathrm{~g} / \mathrm{dl}$ & No reference \\
\hline UK & $\begin{array}{l}\text { Recurrent bacterial infections } \\
\text { despite } 3 \text { months of continuous } \\
\text { oral antibiotic treatment }\end{array}$ & $\begin{array}{l}\text { Failure to respond to } \\
\text { polysaccharide vaccine }\end{array}$ & $\begin{array}{l}\text { IgG below normal, with } \\
\text { impossible reversal of the } \\
\text { hypo-IgG cause or with } \\
\text { contraindications to such } \\
\text { reversal or }<5 \text { g/l (for non- } \\
\text { Hodgkin lymphoma, CLL, } \\
\text { MM, or other, after ruling } \\
\text { out paraproteins)* }\end{array}$ & Panel decision \\
\hline Canada & $\begin{array}{l}\text { One invasive or life- } \\
\text { threatening bacterial infection } \\
\text { (e.g., pneumonia, meningitis, } \\
\text { sepsis) in the previous year; } \\
\text { recurrent, severe bacterial } \\
\text { infections; clinically active } \\
\text { bronchiectasis confirmed by } \\
\text { radiology }\end{array}$ & No reference & $\begin{array}{l}\text { Decreased IgG level or } \\
\text { insufficient production } \\
\text { of IgG }\end{array}$ & $\begin{array}{l}\text { Assessment by } \\
\text { a physician specializing in } \\
\text { immunodeficiency, indicating } \\
\text { a significant antibody defect } \\
\text { that would benefit from } \\
\text { immunoglobulin replacement }\end{array}$ \\
\hline Australia & $\begin{array}{c}\text { Recurrent or severe bacterial } \\
\text { infections }\end{array}$ & No reference & $\begin{array}{l}\text { IgG below normal } \\
\text { (at least in } 2 \text { tests), with } \\
\text { impossible reversal of the } \\
\text { hypo-IgG cause or with } \\
\text { contraindications to such } \\
\text { reversal }\end{array}$ & $\begin{array}{l}\text { The specialists that present } \\
\text { diagnoses or reviews are } \\
\text { limited to hematologists, } \\
\text { immunologists, pediatricians, } \\
\text { oncologists, and general } \\
\text { medicine physicians }\end{array}$ \\
\hline
\end{tabular}

\section{References}

1. Patel SY, Carbone J, Jolles S (2019): The Expanding Field of Secondary Antibody Deficiency: Causes, Diagnosis, and Management. Front Immunol 10: 33.

2. Na I-K, Buckland M, Agostini C, et al. (2019): Current clinical practice and challenges in the management of secondary immunodeficiency in hematological malignancies. Eur J Haematol 102: 447-456.

3. Benbrahim O, Viallard JF, Choquet S, et al. (2019): The use of octagam and gammanorm in immunodeficiency associated with hematological malignancies: a prospective study from 21 French hematology departments. Hematology 24: 173182.

4. Więsik-Szewczyk E, Ziętkiewicz M, Matyja-Bednarczyk A, et al. (2018): The first Polish cohort of adult patients with common variable immunodeficiency from 4 specialized centers: do we provide standards of care? Pol Arch Intern Med 128: 563-566.

5. Korzeniowska M, Więsik-Szewczyk E, Jahnz-Różyk K (2018): Opis przypadku chorego na przewlekłą białaczkę limfocytową i ciężkie zapalenie płuc - jak nie przeoczyć wtórnego niedoboru przeciwciał. [Case report of a patient with chronic lymphocytic leukemia and severe pneumonia - how not to miss a secondary antibody deficiency]. Alergologia i Immunologia Współczesna 41: 35-41.

6. Jahnz-Rozyk K, Roliński J, Siedlar M, et al. (2019): Secondary immunodeficiencies - do we need systemic solutions. JHPOR 1: 2299124.

7. https://www.gov.pl/web/zdrowie/programy-lekowe (access: 4.09.2019)
8. Dhalla F, Misbah SA (2015): Secondary antibody deficiency. Curr Opin Allergy Clin Immunol 15: 505-513.

9. Ueda M, Berger M, Gale RP, Lazarus HM (2018): Immunoglobulin therapy in hematologic neoplasms and after hematopoietic cell transplantation. Blood Rev 32: 106-115.

10. Morrison VA (2010): Infectious complications of chronic lymphocytic leukaemia: pathogenesis, spectrum of infection, preventive approaches. Best Pract Res Clin Haematol 23: 145153.

11. Freeman JA, Crassini KR, Best OG, et al. (2013): Immunoglobulin $\mathrm{G}$ subclass deficiency and infection risk in $150 \mathrm{pa}-$ tients with chronic lymphocytic leukemia. Leuk Lymphoma 54: 99-104.

12. Rozman C, Montserrat E, Vińolas N (1988): Serum immunoglobulins in B-chronic lymphocytic leukemia. Natural history and prognostic significance. Cancer 61: 279-283.

13. Blimark C, Holmberg E, Mellqvist UH, et al. (2015): Multiple myeloma and infections: a population-based study on 9253 multiple myeloma patients. Haematologica 100: 107-113.

14. Karlsson J, Andréasson B, Kondori N, et al. (2011): Comparative study of immune status to infectious agents in elderly patients with multiple myeloma, Waldenstrom's macroglobulinemia, and monoclonal gammopathy of undetermined significance. Clin Vaccine Immunol 18: 969-977.

15. Nucci M, Anaissie E (2009): Infections in patients with multiple myeloma in the era of high - dose therapy and novel agents. Clin Infect Dis 49: 1211-1225.

16. Savage DG, Lindenbaum J, Garret TJ (1982): Biphasic pattern of bacterial infection in multiple myeloma. Ann Intern Med 96: 47-50. 
17. Perri RT, Hebbel RP, Oken MM (1981): Influence of treatment and response status on infection risk in multiple myeloma. Am J Med 71: 935-940.

18. Bourassa-Blanchette S, Knoll G, Tay J, et al. (2017): A national survey of screening and management of hypogammaglobulinemia in Canadian transplantation centres. Transpl Infect Dis 19: e12706.

19. Ullmann AJ, Schmidt-Hieber M, Bertz H, et al. (2016): Infectious diseases in allogeneic haematopoietic stem cell transplantation: prevention and prophylaxis strategy guidelines 2016. Ann Hematol 95: 1435-1455.

20. Petrov AA, Traister RS, Crespo MM, et al. (2018): A Prospective Observational Study of Hypogammaglobulinemia in the First Year After Lung Transplantation. Transplant Direct 4: e372.

21. Greco R, Ciceri F, Noviello M, et al. (2018): Immune monitoring in allogeneic hematopoietic stem cell transplant recipients: a survey from the EBMT-CTIWP. Bone Marrow Transplant 53: 1201-1205.

22. Perales MA, van den Brink MR (2012): Immune recovery after allogeneic hematopoietic stem cell transplantation: is it time to revisit how patients are monitored? Biol Blood Marrow Transplant 18: 1617-1619.

23. Yamazaki R, Kikuchi T, Kato J, et al. (2018): Recurrent bacterial pneumoniae due to immunoglobulin G2 subclass deficiency after allogeneic hematopoietic stem cell transplantation: efficacy of immunoglobulin replacement. Transpl Infect Dis 20: e12863.

24. Sureda A, Bader P, Cesaro S, et al. (2015): Indications for allo- and auto-SCT for haematological diseases, solid tumours and immune disorders: current practice in Europe. BMT 50: 1037-1056.

25. Cooper N, Davies EG, Thrasher AJ (2009): Repeated courses of rituximab for autoimmune cytopenias may precipitate profound hypogammaglobulinaemia requiring replacement intravenous immunoglobulin. Br J Haematol 146: 120-122.

26. Diwakar L, Gorrie S, Richter A, et al. (2010): Does rituximab aggravate pre-existing hypogammaglobulinaemia? J Clin Pathol 63: 275-277.

27. Casulo C, Maragulia J, Zelenetz AD (2013): Incidence of hypogammaglobulinemia in patients receiving rituximab and the use of intravenous immunoglobulin for recurrent infections. Clin Lymphoma Myeloma Leuk 13: 106-111.

28. Wijetilleka S, Mukhtyar C, Jayne D, et al. (2019): Immunoglobulin replacement for secondary immundeficiency after B-cell targeted therapies in autoimmune rheumatic diseases: systematic literature review. Autoimmun Rev 18: 535-541.

29. Shah S, Jaggi K, Greenberg K, Geetha D (2017): Immunoglobulin levels and infection risk with rituximab induction for anti-neutrophil cytoplasmic antibody-associated vasculitis. Clin Kidney J 10: 470-474.

30. Tallantyre EC, Whittam DH, Jolles S, et al. (2018): Secondary antibody deficiency: a complication of anti-CD20 therapy for neuroinflammation. J Neurol 265: 1115-1122.

31. Tudesq JJ, Cartron G, Rivičre S, et al. (2018): Clinical and microbiological characteristics of the infections in patients treated with rituximab for autoimmune and/or malignant hematological disorders. Autoimmun Rev 17: 115-124.

32. van Vollenhoven RF, Emery P, Bingham CO 3rd, et al. (2013): Long-term safety of rituximab in rheumatoid arthritis: 9.5-year follow-up of the global clinical trial programme with a focus on adverse events of interest in RA patients. Ann Rheum Dis 72: 1496-1502.
33. van Vollenhoven RF, Fleischmann RM, Furst DE, et al. (2015): Long term safety of rituximab: final report of the Rheumatoid Arthritis Global Clinical Trial Program over 11 years. J Rheumatol 42: 1761-1776.

34. Cortazar FB, Pendergraft 3rd WF, Wenger J, et al. (2017): Effect of continuous B cell depletion with rituximab on pathogenic autoantibodies and total IgG levels in antineutrophil cytoplasmic antibody associated vasculitis. Arthrits Rheum 69: 1045-1053.

35. Marco H, Smith RM, Jones MB et al. (2014): The effect of rituximab therapy on immunoglobulin levels in patients with multisystem autoimmune disease. BMC Musculoskeletal Disord 15: 178.

36. Venhoff N, Effelsberg NM, Salzer U, et al. (2012): Impact of rituximab on immunoglobulin concentrations and B cell numbers after cyclophosphamide treatment in patients with ANCA associated vasculitides. PLoS One 7: e37626.

37. Merrill JT, Wallace DJ, Wax S, et al. (2018): Efficacy and Safety of Atacicept in Patients With Systemic Lupus Erythematosus: Results of a Twenty-Four-Week, Multicenter, Randomized, Double-Blind, Placebo-Controlled, Parallel-Arm, Phase IIb Study. Arthritis Rheumatol 70: 266-276.

38. Smilek DE, Lim N, Ding L, et al. (2017): Correlation of hypogammaglobulinaemia with proteinuria, and the relationship between hypogammaglobulinaemia and infection in active lupus nephritis. Lupus Sci Med 4: e000229.

39. Sewell WA, Kerr J, Behr - Gross ME, et al. (2014): European consensus proposal for immunoglobulin therapies. Eur J Immunol 44: 2207 - 2214.

40. Jolles S, Chapel H, Litzman J (2016): When to initiate immunoglobulin replacement therapy (IGRT) in antibody deficiency: a practical approach. Clin Exp Immunol 188: 333-341.

41. Dhalla F, Lucas M, Schuh A, et al. (2014): Antibody deficiency secondary to chronic lymphocytic leukemia: should patients be treated with prophylactic replacement immunoglobulin? J Clin Immunol 34: 277-282.

42. Jolles S, Sewell WAC, Misbah SA (2005): Clinical uses of intravenous immunoglobulin. Clin Exp Immunol 142: 1-11.

43. Orange JS, Ballow M, Stiehm ER, et al. (2012): Use and interpretation of diagnostic vaccination in primary immunodeficiency: a working group report of the Basic and Clinical Immunology Interest Section of the American Academy of Allergy, Asthma \& Immunology. J Allergy Clin Immunol 130 (3 Supl): S1-24.

44. Pasiarski M, Rolinski J, Grywalska E, et al. (2014): Antibody and Plasmablast Response to 13-Valent Pneumococcal Conjugate Vaccine in Chronic Lymphocytic Leukemia Patients - Preliminary Report. PLoS One 9: e114966.

45. Edgar JDM, Richter AG, Huissoon AP, et al. (2018): Prescribing Immunoglobulin Replacement Therapy for Patients with Non-classical and Secondary Antibody Deficiency: an Analysis of the Practice of Clinical Immunologists in the UK and Republic of Ireland. J Clin Immunol 38: 204-213.

46. Parker AP, Bradley C, Harding S, et al. (2018): Measurement and interpretation of Salmonella typhi Vi IgG antibodies for the assessment of adaptive immunity. J Immunol Methods 459: 1-10.

47. van Assen S, Agmon-Levin N, Elkayam O et al. (2011): EULAR recommendations for vaccination in adult patients with autoimmune inflammatory rheumatic diseases. Ann Rheum Dis 70: 414-422.

48. Rieger CT, Liss B, Mellinghoff S, et al. (2018): Anti-infective vaccination strategies in patients with hematologic 
malignancies or solid tumors - Guideline of the Infectious Diseases Working Party (AGIHO) of the German Society for Hematology and Medical Oncology (DGHO). Ann Oncol 29: 1354-1365.

49. Ullmann AJ, Schmidt-HieberM, Bertz H, et al. (2016): Infectious diseases in allogeneic haematopoietic stem cell transplantation: prevention and prophylaxis strategy guidelines 2016. Ann Hematol 95: 1435-1455.

50. Piekarska A, Giebel S, Basak GW, et al. (2017): Szczepienia ochronne u chorych dorosłych po przeszczepieniu komórek krwiotwórczych - zalecenia sekcji do spraw zakażeń PALG. Acta Haematologica Polonica 48: 1-9.

51. Svensson T, Kättström M, Hammarlund Y, et al. (2018): Pneumococcal conjugate vaccine triggers a better immune response than pneumococcal polysaccharide vaccine in patients with chronic lymphocytic leukemia A randomized study by the Swedish CLL group. Vaccine 36: 3701-3707.

52. Buch MH, Smolen JS, Betteridge M, el al. (2011): Updated consensus statement on the use of rituximab in patients with rheumatic arthritis. Ann Rheum Dis 70: 909e20.

53. Cooperative Group for the study of Immunoglobulin in Chronic Lymphocytic Leukemia (1988): Intravenous immunoglobulin for the prevention of infection in chronic lymphocytic leukemia. A randomized controlled clinical trial. N Engl J Med 319: 902-907.

54. Griffiths H, Brennnan V, Lea J, et al. (1989): Cross-over study immunoglobulin replacement therapy in patients with low - grade B-cell tumors. Blood 73: 366-368.

55. Chapel H, Dicato M, Gamm H, et al. (1994): Immunoglobulin replacement in patients with chronic lymphocytic leukemia: a comparison of two dose regimes. Br J Hematol 88: 2012-2019.

56. Boughton BJ, Jackson N, Lim S, Smith N (1995): Randomised trial of intravenous immunoglobulin prophylaxis for patients with chronic lymphocytic leukemia and secondary hypogammaglobulinemia. Clin Lab Haematol 17: 75-80.

57. Molica S, Musto P, Chiurazzi F, et al. (1996): Prophylaxis against infections with low-dose intravenous immunoglobulins (IVIG) in chronic lymphocytic leukemia. Results of a crossover study. Haematologica 81: 121-126.

58. Chapel HM, Lee M, Hargreaves R, et al. (1994): Randomised trial of intravenous immunoglobulin as prophylaxis against infection in plateau-phase multiple myeloma. The UK Group for Immunoglobulin Replacement Therapy in Multiple Myeloma. Lancet 343: 1059-1063.

59. Musto P, Brugiatelli M, Carotenuto M (1995): Prophylaxis against infections with intravenous immunoglobulins in multiple myeloma. Br J Haematol 89: 945-946.

60. Eichhorst B, Robak T, Montserrat E, et al. (2015): ESMO Clinical Practice Guidelines for diagnosis, treatment and follow-up. Ann Oncol 26: v78-84.

61. Hallek M, Cheson BD, Catovsky D, et al. (2018): iwCLL guidelines for diagnosis, indications for treatment, response assessment, and supportive management of CLL. Blood 131: 2745-2760.

62. Snowden JA, Ahmedzai SH, Ashcroft J, et al. (2011): Guidelines for supportive care in multiple myeloma 2011. Br J Hematol 154: 76-103.

63. Ahn H, Shea B, Hutton B, et al. (2018): Effectiveness of immunoglobulin prophylaxis in reducing clinical complications of hematopoietic stem cell transplantation: a systematic review and meta-analysis. Transfusion 58: 2437-245216.

64. Perez EE, Orange JS, Bonilla F, et al. (2017): Update on the use of immunoglobulin in human disease: a review of evidence. J Allergy Clin Immunol 139: S1-46.
65. Raanani P, Gafter-Gvili A, Paul M, et al. (2008): Immunoglobulin prophylaxis in hematological malignancies and hematopoietic stem cell transplantation. Cochrane Database Syst Rewiev 8: CD006501.

66. Ammann EM, Jones MP, Link BK, et al. (2016): Intravenous immune globulin and thromboembolic adverse events in patients with hematologic malignancy. Blood 127: 200-207.

67. Garduf A (2007): Immunoglobulin treatment for primary antibody deficiencies: advantages of the subcuteneous route. BioDrugs 21: 105-116.

68. Misbah S, Sturzenegger MH, Borte M, et al. (2009): Subcutaneous immunoglobulin: opportunities and outlook. Clin Exp Immunol 1: 51-59.

69. Wasserman RL, Melamed I, Stein MR, et al. (2012): Recombinant human hyaluronidase-facilitated subcutaneous infusion of human immunoglobulins for primary immunodeficiency. J Allergy Clin Immunol 130: 951-957.

70. Wasserman RL (2014): Overview of recombinant human hyaluronidase facilitated subcutaneous infusion of $\mathrm{IgG}$ in primary immunodeficiencies. Immunotherapy 6: 553-567.

71. Shabaninejad H, Asgharzadeh A, Rezaei N, Rezapoor A (2016): A comparative study of intravenous immunoglobulin and subcutaneous immunoglobulin in adult patients with primary immunodeficiency diseases: a systematic review and meta-analysis. Expert Rev Clin Immunol 12: 595-602.

72. Compagno N, Cinetto F, Semenzato G, Agostini C (2014): Subcutaneous immunoglobulin in lymphoproliferative disorders and rituximab-related secondary hypogammaglobulinemia: a single-center experience in 61 patients. Haematologica 99: 1101-1106.

73. Vacca A, Melaccio A, Sportelli A, et al. (2018): Subcutaneous immunoglobulins in patients with multiple myeloma and secondary hypogammaglobulinemia: a randomized trial. Clin Immunol 191: 110-115.

74. Dimou M, Iliakis T, Maltezas D, et al. (2018): Efficacy-safety of Facilitated Subcutaneous Immunoglobulin in Immunodeficiency Due to Hematological Malignancies. A Single-Center Retrospective Analysis. Anticancer Res 38: 4187-4191.

75. Reiser M, Borte M, Huscher D, et al. (2017): Management of patients with malignancies and secondary immunodeficiencies treated with immunoglobulins in clinical practice: Longterm data of the SIGNS study. Eur J Haematol 99: 169-177.

76. Agostini C, Blau IW, Kimby E, Plesner T (2016): Prophylactic immunoglobulin therapy in secondary immune deficiency - an expert opinion. Expert Rev Clin Immunol 12: 921-926.

77. Australian National Blood Authority Acquired Hypogammaglobulinaemia Secondary to Haematological Malignancies, or Post-Haemopoietic Stem Cell Transplantation (HSCT): BloodStar (2018) (access: 4.09.2019).

78. Alberta Ministry of Health (2018): Alberta Ministry of Health, Shared Health Manitoba, Saskatchewan Ministry of Health Criteria for the Clinical Use of Immune Globulin. https://www.ihe.ca/download/criteria_for_the_clinical_use_ of_immune_globulin_first_edition.pdf (access: 1.09.2019).

79. Department of Health, UK (2011): Clinical guidelines for immunoglobulin use: update to second edition (access: 1.09.2019).

80. European Medicines Agency (2018): European Medicines Agency Guideline on Core SmPC for Human Normal Immunoglobulin for Intravenous Administration (IVIg). https:// www.ema.europa.eu/documents/scientific-guideline/guideline-core-smpc-human-normal-immunoglobulin-intravenous-administration-ivig-rev-5_en.pdf (access 1.09.2019) 